\title{
An exploratory study on prevalence of self-medication among the students of selected university, Rajpura, Punjab
}

\author{
Kashish Malhotra $^{1 *}$, Komal Rani ${ }^{1}$, Parminder Kaur ${ }^{1}$, Navdeep Kaur ${ }^{2}$
}

\author{
${ }^{1}$ Nursing 4th year, Chitkara University, Rajpura, Punjab, India \\ ${ }^{2}$ Department of Nursing, Chitkara University, Himanchal Pradesh, India
}

Received: 08 September 2020

Accepted: 07 October 2020

\author{
*Correspondence: \\ Dr. Kashish Malhotra, \\ Email: kashishm6@gmail.com
}

Copyright: (c) the author(s), publisher and licensee Medip Academy. This is an open-access article distributed under the terms of the Creative Commons Attribution Non-Commercial License, which permits unrestricted non-commercial use, distribution, and reproduction in any medium, provided the original work is properly cited.

\begin{abstract}
Background: Self-medication is defined as the use of non-prescription drugs by an individual for the treatment of selfdiagnosed ailments. The aim of the study is to assess the prevalence of self-medication and to explore the factors leading to self-medication among the students of selected university. The aim of this research was to assess the prevalence of self-medication among students, to explore the factors leading to self-medication among students, and to find out the association between the prevalence of self-medication and selected socio-demographic variables.

Methods: It was an exploratory design. 500 students were selected by using a convenient sampling method. Students of selected university were included in the study to assist the prevalence of self-medication and to explore the factors leading to self-medication. A self- structured questionnaire was used for collecting data.

Result: Self-medication was reported by $88.4 \%$ of students. The most common ailment for which self-medication is being taken was pain $(84.40 \%)$ followed by respiratory $(83.80 \%)$. Most students take self-medication occasionally $(77.30 \%)$. Only $5.40 \%$ of students take self-medication daily. The most common factor which leads to self-medication in students was confidence in self-medication (83.4\%) followed by family and friend's advice (82.0\%). There was no association between socio-demographic variables and the prevalence of self-medication except association seen with gender.

Conclusion: The study concluded that the prevalence of self-medication in students of selected university was $88.4 \%$ and self-confidence is the most common factor which leads to self-medication. Self-medication is an important issue among students.
\end{abstract}

Keywords: Self-medication, Ailment, Over the counter drugs, Questionnaire, Self-diagnosed, Adverse-reaction

\section{INTRODUCTION}

Self-medication is defined as the use of non-prescription drugs by an individual for the treatment of self-diagnosed ailments. Non-prescription drugs are also known as overthe-counter drugs, which can be bought without a doctor's prescription. ${ }^{1}$ When these medications are used wisely, they are risk-free and treat the ailments, but when they are taken in larger amounts, they could cause serious health problems. The World Health Organization (WHO) has described self-medication as the utility by which individuals treat their ailments with medicines that are approved and accessible without a prescription. The foremost widely used self-medicated substances are overthe-counter drugs used to treat minor ailments at home. ${ }^{2}$ In 1995 the WHO expert committee declared that selfmedication is commonly practiced in both developed and developing nations. In countries like India, self-medication is a basic practice because it provides a nominal alternative for people. ${ }^{3}$ Self-medication has a very important place within the healthcare system, as individuals recognize the responsibility of their health. Enhancement in people's cognition, knowledge, level of education, and 
socioeconomic status in many countries form a rationale for successful self-medication. Self-medication is a component of self-care. There are some benefits of selfmedication like convenience, rapid access to treatment, cheaper, reduced burden on hospitals and community health centers, educational opportunities, reducing absenteeism at colleges, schools, or work. To take selfmedication consumers should have knowledge related to drugs, their indications, contraindications, and side effects. Some risks for taking self-medication are incorrect selfdiagnosis, incorrect choice of therapy, failure to seek appropriate medical advice, delay in treatment, the progression of the disease, adverse effects, prolonged use of drugs, inadequate or excessive drug dosage, drug dependence, and drug interactions. ${ }^{2}$ According to a recent community-based study done in 2016 , the prevalence of self-medication in developing countries varies from $12 \%$ to as high as $73 \%$ and prevalence had increased from $31 \%$ in 1997 to $71 \%$ in 2011. The prevalence among Asian countries, like Nepal 59\%, Pakistan 51\%, Sri Lanka 64\%, Bangladesh $80 \% .{ }^{4,5}$ Self-medication is highly prevalent in India. In coastal regions of South India, the prevalence was $71 \%$, while in Delhi prevalence was $92.8 \%{ }^{6,7}$ Reasons for self-medication are previous experiences, advice of family or friends, confidence in self-medication, timing saving, non-availability of transport, convenience, etc. some other sources are internet, books, pharmacist, and suggestions from an advertisement in the newspaper or popular magazines. ${ }^{8}$ The most common OTC medications are antipyretics, analgesics, Non-steroidal anti-inflammatory drugs (NSAIDs), antihistamines, laxatives, vitamin supplements, and cough suppressants. Using antibiotics as self-medication may lead to drug resistance which further leads to fatal conditions. The most widely used selfmedications are OTC drugs and dietary supplements. Analgesics, anti-malarial, antibiotics, and cough syrups are used for self-administration. Self-medication is not restricted to OTC medicines only, patients self-medicate with prescription medicines also. These are medicines that may have been prescribed and leftover from an old treatment episode or bought directly from the community pharmacies without a prescription. ${ }^{4}$

\section{METHODS}

An exploratory study was carried out during the period of March to June 2019 among 515 study subjects. Only 500 of the questionnaires were filled correctly. Convenient sampling technique was used to select the sample. A selfstructured questionnaire was used to collect data.

The first part of the questionnaire included basic sociodemographic data (age, gender, stream of education, year of course, educational status of the mother, educational status of the father, place of present stay) about respondents. The second part included questionnaire to assess the prevalence of self-medication (prevalence, common ailments, frequency, and adverse reactions) and the third part included questionnaire to explore the factors leading to self-medication.

The questionnaire was validated by experts including language experts for English to ascertain content appropriateness, clarity, and relevance. The prepared tool for data collection along with problem statement, objectives, operational definition designed was validated by 5 experts. Informed consent was taken from the subjects after discussing the purpose and objectives of the study. The confidentiality of the data was maintained.

All data collected were entered into Statistical package for social sciences (SPPS) software. Descriptive analysis, inferential statistics, and chi-square tests were employed for evaluation.

\section{RESULTS}

Out of 500 study subjects, females were $279(55.8 \%)$ and males were $221(44.2 \%)$. The majority $(65.6 \%)$ students belong to the age group 19-20 years and the least belong to 23-24 years age group (1\%). 37.6\% of students were from stream Computer science engineering (CSE) and the least subjects were from Mass Communication (0.2\%). About $40.36 \%$ of students were from 2 nd year. The education status of most of the parents was graduation and above (mother-71.6\%, father-78.8\%). Most of the students were residing in the hostel $(52.8 \%)$ (Table 1$)$.

The prevalence of self-medication among students of selected university was $88.4 \%$ (Table 2 ).

The majority of the students take self-medication for pain $(84.40 \%)$ followed by respiratory $(83.80 \%)$ and least for gastrointestinal ailments $(81.80 \%)$. (Figure 1) Most students take self-medication occasionally $(77.30 \%)$ followed by frequently $(17.10 \%)$ and only $5.40 \%$ of students take self-medication daily (Figure 2).

Only $8.37 \%$ of students had an adverse reaction while taking self-medication and $91.62 \%$ of students had no adverse reaction while taking self-medication (Figure 3).

Factors leading to self-medication among students were confidence in self-medication (83.4\%), family and friend's advice $(82.0 \%)$, previous prescription $(79.2 \%)$, convenience $(74.2 \%)$, doctor far away from home $(39 \%)$, and costly medications prescribed by doctors $(33.03 \%)$ (table 3).

There was a significant association of gender with the prevalence of self-medication among students of selected university, Punjab and there is no significant association of age, a stream of education, year of course, place of present stay, education status of the mother, education status of father with the prevalence of self-medication among students of selected university, Punjab (Table 4). 
Table 1: Frequency and percentage distribution of socio-demographic variables.

\begin{tabular}{|c|c|c|c|}
\hline Variables & Opts & Percentage distribution (\%) & Frequency \\
\hline \multirow{4}{*}{ Age (in years) } & 19 to 20 & 65.6 & 328 \\
\hline & 21 to 22 & 33.4 & 167 \\
\hline & 23 to 24 & 1.0 & 5 \\
\hline & 24 to 25 & 0.0 & 0 \\
\hline \multirow{2}{*}{ Gender } & Male & 44.2 & 221 \\
\hline & Female & 55.8 & 279 \\
\hline \multirow{13}{*}{ Stream of education } & B. Com & 4.0 & 20 \\
\hline & BBA & 10.4 & 52 \\
\hline & BCA & 0.8 & 4 \\
\hline & BPT & 2.0 & 10 \\
\hline & CSE & 37.6 & 188 \\
\hline & HA & 0.4 & 2 \\
\hline & HM & 12.2 & 61 \\
\hline & Mass communication & 0.2 & 1 \\
\hline & MBA & 3.4 & 17 \\
\hline & ME & 2.2 & 11 \\
\hline & Nursing & 14.8 & 74 \\
\hline & OPT & 1.0 & 5 \\
\hline & Pharmacy & 11.0 & 55 \\
\hline \multirow{6}{*}{ Year of course } & One & 25.4 & 127 \\
\hline & Two & 40.6 & 203 \\
\hline & Three & 27.0 & 135 \\
\hline & Four & 5.6 & 28 \\
\hline & Five & 1.2 & 6 \\
\hline & Six & 0.2 & 1 \\
\hline \multirow{4}{*}{ Educational status of mother } & Primary & 1.4 & 7 \\
\hline & Matric & 13.6 & 68 \\
\hline & Senior secondary & 13.4 & 67 \\
\hline & Graduation and above & 71.6 & 358 \\
\hline \multirow{4}{*}{ Educational status of father } & Primary & 0.6 & 3 \\
\hline & Matric & 4.4 & 22 \\
\hline & Senior secondary & 8.6 & 43 \\
\hline & Graduation and above & 78.8 & 394 \\
\hline \multirow{3}{*}{ Place of present stay } & Hostel & 52.8 & 264 \\
\hline & Home & 45.4 & 227 \\
\hline & Paying guest (PG) & 1.6 & 8 \\
\hline
\end{tabular}

Table 2: Prevalence of self-medication of Chitkara University, Rajpura, Punjab.

\begin{tabular}{|llll|}
\hline Self medication & & Percentage $(\%)$ & Frequency \\
\hline Prevalence & Yes & 88.4 & 442 \\
\cline { 2 - 3 } & No & 11.6 & 58 \\
\hline
\end{tabular}

Table 3: Factors leading to self-medication among students.

\begin{tabular}{|lll|}
\hline Variables & Percentage $\mathbf{( \% )}$ & Frequency \\
\hline Doctor far away from home & 39 & 195 \\
\hline Confidence in self-medication & 83.4 & 417 \\
\hline Previous Prescriptions & 79.2 & 396 \\
\hline Family and Friends advice & 82.0 & 410 \\
\hline Costly medications prescribed by doctors & 33.03 & 146 \\
\hline Convenience & 74.2 & 371 \\
\hline
\end{tabular}


Table 4: Association of selected socio-demographic variables with self-medication.

\begin{tabular}{|c|c|c|c|c|c|c|c|c|}
\hline \multicolumn{2}{|c|}{ Demographic variables } & \multicolumn{2}{|c|}{ Do you take self medication } & \multicolumn{5}{|c|}{ Prevalence } \\
\hline & Opts & No & Yes & Chi Test & $p$ value & df & $\begin{array}{l}\text { Table } \\
\text { value }\end{array}$ & Result \\
\hline \multirow{2}{*}{ Gender } & Male & 36 & 185 & \multirow{2}{*}{8.494} & \multirow{2}{*}{0.004} & \multirow{2}{*}{1} & \multirow{2}{*}{3.841} & \multirow{2}{*}{ Significant } \\
\hline & Female & 22 & 257 & & & & & \\
\hline
\end{tabular}

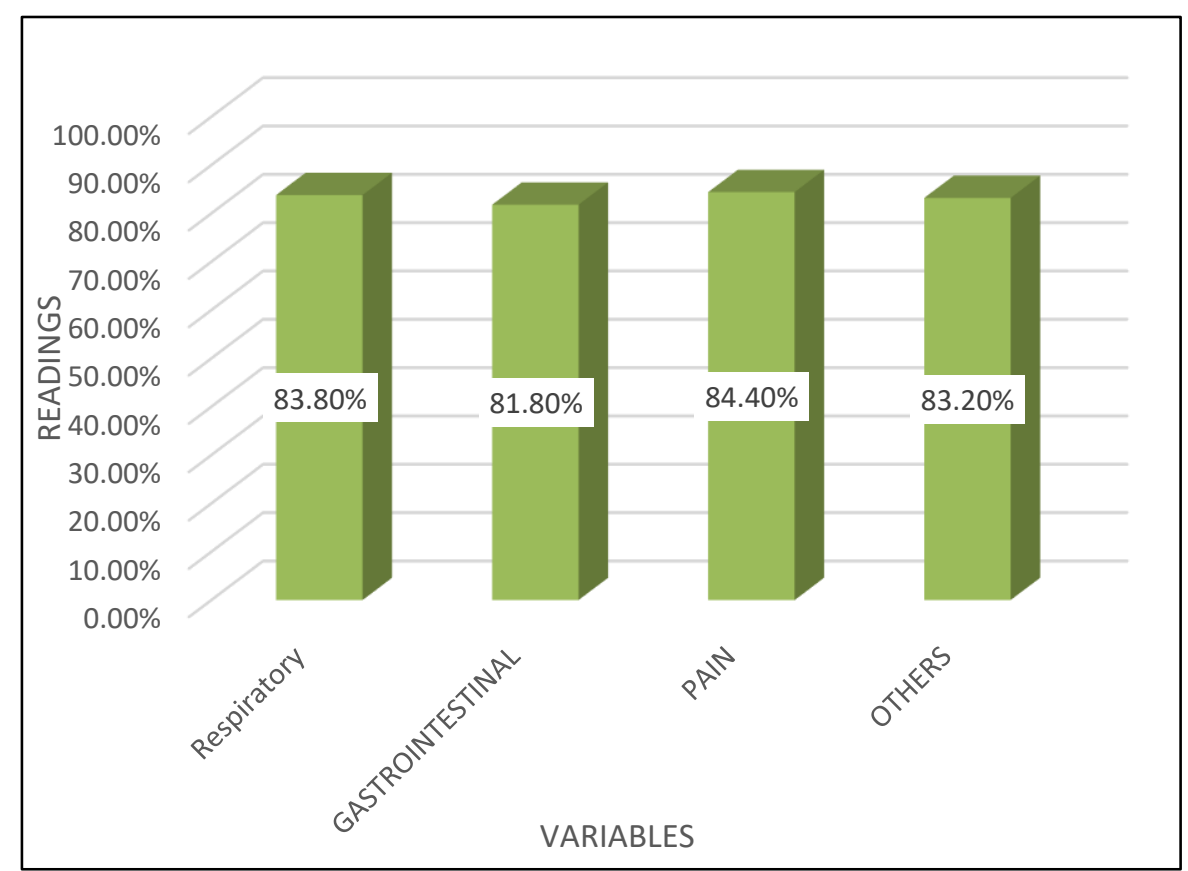

Figure 1: Common ailments for which students take self-medication.

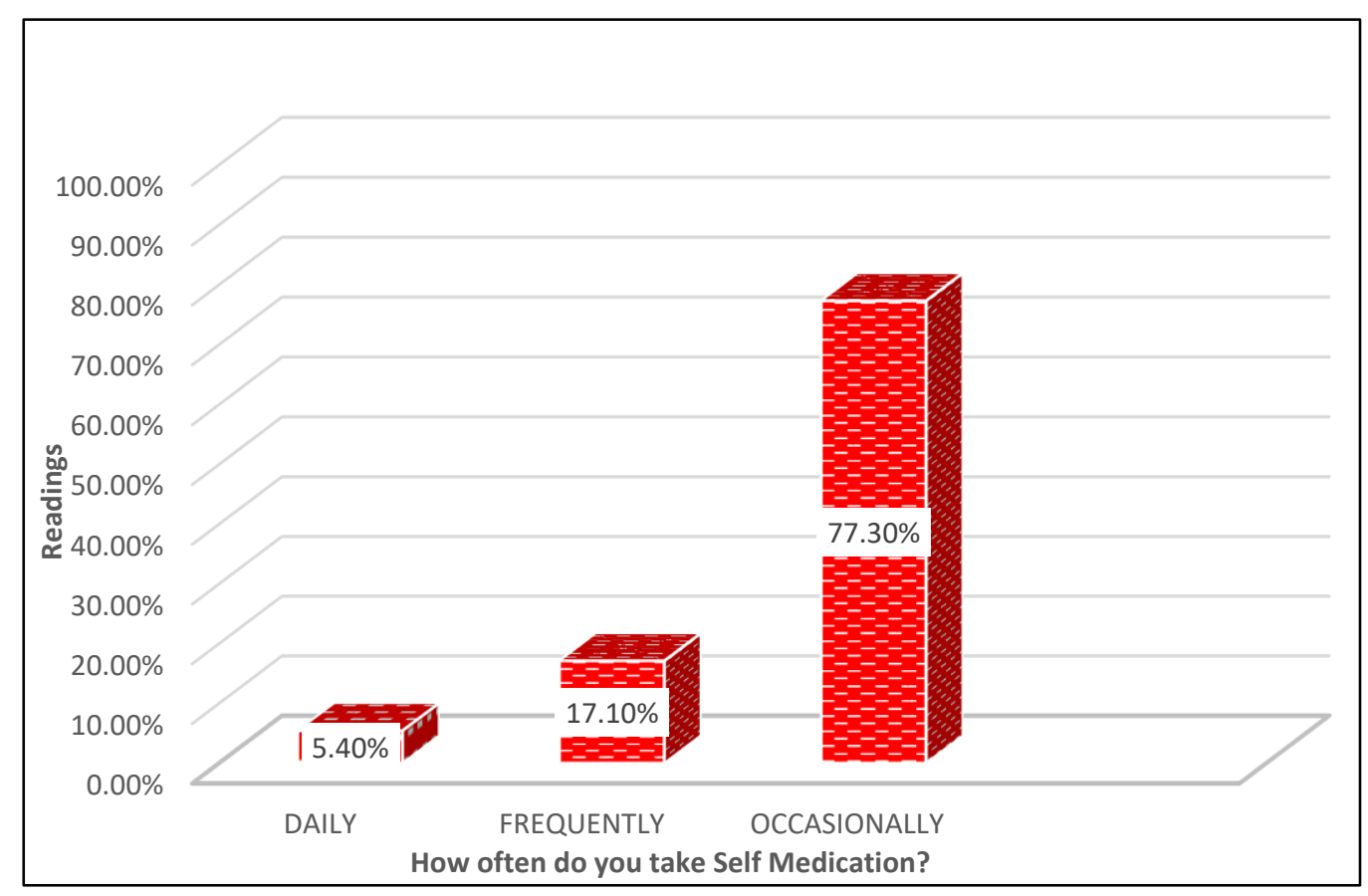

Figure 2: Frequency of self-medication among students. 


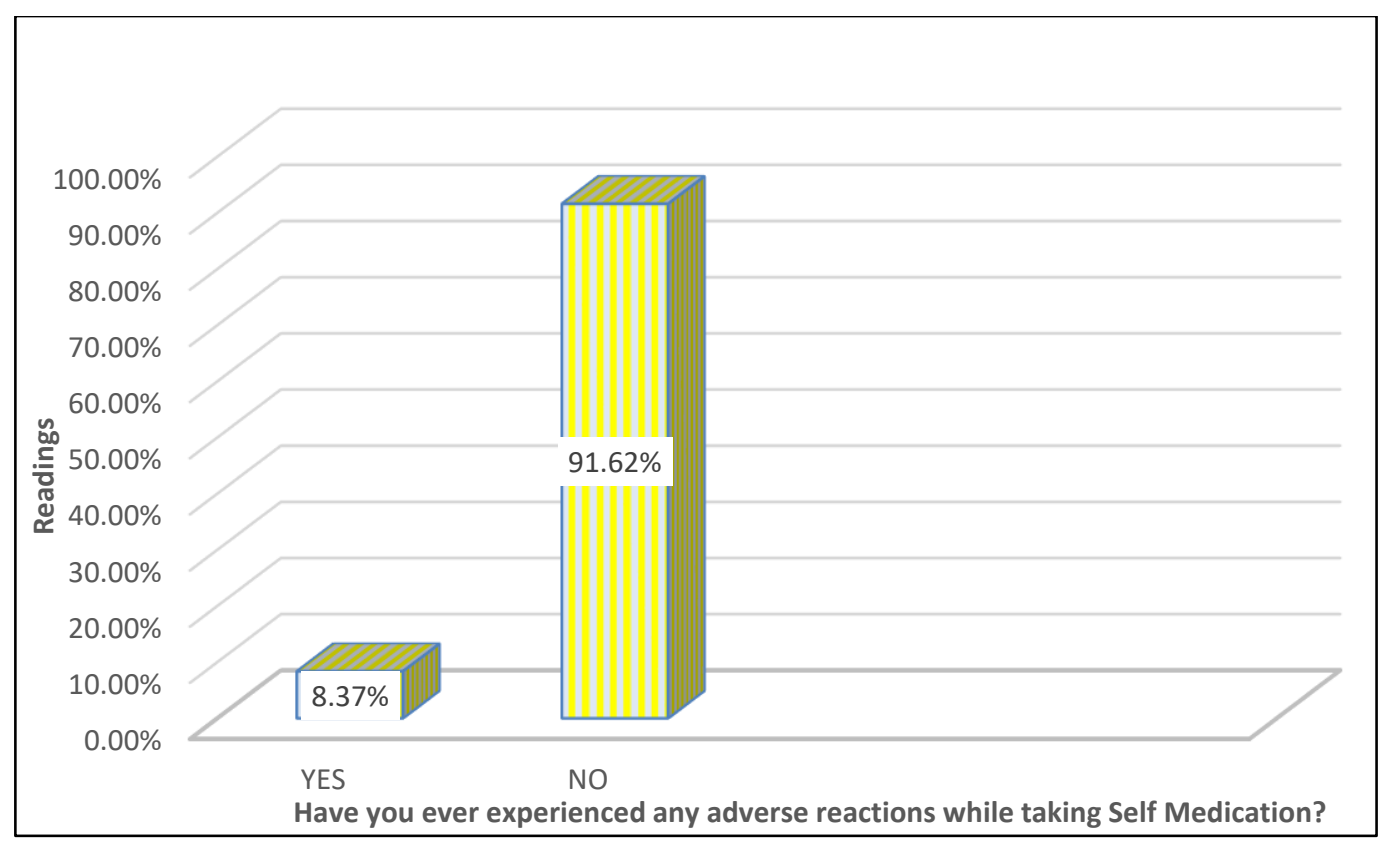

Figure 3: Adverse reactions while taking self-medication.

\section{DISCUSSION}

Based upon findings from the analysis of data, discussion of the present study was done with the objectives of the research problem and discussed with reference to results observed by the researchers.

The present study was carried out among students selected university, Punjab, to assess the prevalence of selfmedication and to explore factors leading to selfmedication. A sample of a total of 500 students was taken for study. The analysis was done using SPPS software.

In our present study sample size of 500 students was selected by using a convenient sampling technique. The ages of the study sample ranged from 18-25 years of age, of which $221(44.2 \%)$ were male and $279(55.8 \%)$ were female whereas a study was conducted among students from different medical and nursing colleges of Punjab. The sample size of 403 students was selected by using randomization. Ages of the students inclined from 17-23 years, from which $140(34.7 \%)$ were males and 263 $(65.3 \%)$ were females. ${ }^{9}$

In our present study, it had been found that among 500 sample sizes, self-medication was prevalent among a maximum of $88.4 \%$ of the respondents. Similar results were observed in another study that was being conducted among 100 students of Rayat-Bahra College of Nursing, Mohali. The results of that study showed that $73 \%$ of the respondents were prevalent in self-medication. ${ }^{10}$

In our present study, headache $(84.40 \%)$, cold $(83.80 \%)$, fever $(83.20 \%)$, acidity $(81.8 \%)$ was the most common reasons for self-medication. In another study which was conducted among 207 students from two universities of
Karachi, revealed that headache (62.3\%) and fever (49.8\%) were the most common reasons for self-medication. ${ }^{11}$

In this present study, the prevalence of self-medication was $88.4 \%$. The main factors that were leading to selfmedication were confidence in self-medication $(83.4 \%)$, family and friends' advice $(82.0 \%)$, and previous prescription (79.2\%). Another study conducted among 122 medical students in a tertiary care center revealed that the main factors leading to self-medication were ailments minor for the consultant $(63.1 \%)$ and previous experience of the same illness $(58.1 \%) .^{12}$

Similarly, in another study, major factors leading to selfmedication were simple disease $(56.50 \%)$, easy availability of drugs $(50.80 \%)$, self-decision $(31.40 \%)$, and timesaving $(28.00 \%){ }^{13}$

In this present study, it was concluded that there was no association between socio-demographic variables and the prevalence of self-medication except association seen with gender. On the contrary, a study which was conducted among 2000 university students of Southwestern Nigeria revealed that there was a significant association between the prevalence of self-medication and age, gender, and educational status. ${ }^{14}$

\section{CONCLUSION}

Study concluded that prevalence of self-medication among students of selected university was $84.40 \%$. Pain $(84.40 \%)$ was the most common reason for the self-medication followed by cough and cold $(83.80 \%)$. About $5.40 \%$ of the students practice self-medication daily. Factors leading to self-medication among students was confidence in self- 
medication (83.04\%) followed family and friends' advice $(82.0 \%)$.

\section{ACKNOWLEDGEMENTS}

The researchers would like to express their utmost appreciation to the participants for their valuable time that they have spent to take part in the study.

\section{Funding: No funding sources}

Conflict of interest: None declared

Ethical approval: The study was approved by the Institutional Ethics Committee

\section{REFERENCES}

1. Self-medication. 2000. https://en.wikipedia.org/wiki/ Self-medication. Assessed 20 March, 2019.

2. World Health Organization. (2012b, June 17). Guidelines for the regulatory assessment of medicinal products for use in self-medication. https://Apps.Who.Int/Iris/Handle/10665/66154. Assessed 20 March, 2019.

3. Gadekar RD, Gattani PL, Dhande VS. A study of selfmedication among the adult people of the Nanded city, western India. Int J Community Med Public Health. 2017;4:3814-8.

4. Marak A, Borah M, Bhattacharyya H, Talukdar K. A cross sectional study on self-medication practices among the rural population of Meghalaya; 2015. Int J Med Sci Public Health. 2016;5(6):1134-8.

5. Wijesinghe PR, Jayakody RL, Senevirante RA. Prevalence and predictors of self-medication in a selected urban and rural district of Sri Lanka; WHO South-East. Asia J Public Health. 2012;1(1):28-41.

6. V P, Narayanan P, Guddattu V. Self medication practice among urban slum dwellers in Udupi taluk, Karnataka, India. Int $\mathbf{J}$ Pharm Pharm Sci. 2017;9(6):19.

7. Kumar V, Mangal A, Yadav G, Raut D, Singh S. Prevalence and pattern of self-medication practices in an urban area of Delhi, India. Med J. DY Patil Univ. 2015;8(1):16-20.

8. Adhikary M, Tiwari P, Singh S, Karoo C. Study of self-medication practices and its determinants among college students of Delhi University North Campus, New Delhi, India. Int J Med Sci Public Health. 2014;3:406-09.

9. Bhatia MK, Singh R, Singh A, Bhardwaj BL. Knowledge, attitude and practice of self-medication among undergraduate medical students of Punjab. J Med Res. 2017;3(3):151-4.

10. Kaur S, Kaur G, Kaur I. An exploratory study to assess prevalence and pattern of self- medication practices among students of Rayat-Bahra College of Nursing, Mohali. Int J Health Sci Res. 2016;6(1):299-303.

11. Mumtaz Y, Jahangeer, A Mujtaba T, ZafarS, Adnan S. Self-medication among university students of Karachi. J. Liaquat Univ of Med Health Sci. 2011;10(3):102-5.

12. Chhabra R, Deshmukh JB, Tamboli SB, Laxmi B, Deshmukh AC. Study of Self-Medication among Medical Undergraduate Students in a Tertiary Care Hospital, Maharashtra, India. Int J Health Sci Res. 2015;5(12): 190-96.

13. Jain S, Thakur A, Peepre K, Kaushal S, Kasar P. Prevalence of self-medication practices among the residents of urban slums located near govt. medical college, Jabalpur. Int J Community Med Public Health 2018;5:811-7.

14. Osemene K, Lamikanra A. A Study of the Prevalence of Self-Medication Practice among University Students in Southwestern Nigeria. Trop J Pharm Res. 2012;11(4):683-98.

Cite this article as: Malhotra K, Rani K, Kaur P, Kaur N. An exploratory study on prevalence of selfmedication among the students of selected university, Rajpura, Punjab. Int J Basic Clin Pharmacol 2020;9:1695-700. 